\title{
How to Increase the Students' Prosocial Behavior in the Era of Technology?
}

\author{
Abdul Kholiq and M. Solehuddin
}

\begin{abstract}
Development of technology affects many aspects of human life. One of them is its negative impact on prosocial behavior of students. This important behavior must be increased in order to help the students to live adaptively. This research employed qualitative method with ethnographic study and the data was collected through in-depth interview with many school counsellors in Indonesia. The results showed that to improve prosocial behavior can be done in several ways, namely considering its urgency, the impact of technology on prosocial behavior, management of the influencing factors, and the services of guidance and counselling that utilize the enhancement of technology. Thus, the school counsellors are suggested to discover the effectiveness of the ways and invent another new technique to increase prosocial behavior.
\end{abstract}

Index Terms - Guidance and counselling, prosocial behavior, era of technology.

\section{INTRODUCTION}

Technological advances encourage humans to change their lifestyle [1]. Humans must be able to adapt to technological developments so that they are able to adapt to their environment. An example of changes in human lifestyle caused by technological developments is the learning method in school. Currently, the pattern of interaction between teachers and students in schools is different from the era when technology was not yet sophisticated. This happens because the world community accepts technological advances and simultaneously uses it in everyday life. Therefore, this increasingly modern development needs new competencies for teachers in schools related to technology.

Teacher competency in the $21^{\text {st }}$ century is primarily to educate students' soft skills by utilizing technology [2]. These students' skills must be fulfilled by teacher in the school in order to be able to adjust to the current era and even to compete globally. One of the teachers in a school who plays a role in the success of education is a school counsellor or teacher of guidance and counselling. The main task of a school counsellor is to help the development of students to be independent, to adapt to their environment, and develop optimally. Therefore, the current school counsellors have new challenges in term of the development of technology.

Manuscript received May 30, 2019; revised March 1, 2020.

The authors are with the Indonesia University of Education, Bandung, West Java, Indonesia (e-mail: abdulkholiq@upi.edu, msolehuddin@upi.edu).
In developing students, a school counsellor needs to know and identify the opportunities and challenges that arise due to technological developments. School counsellors have the opportunity to use technology to facilitate and support their duties both at school and outside of the school. They work with school management and parents collaboratively. Such comprehensive communication can be assisted by easy and integrated technological facilities. In addition, school counsellors can also use technology as a medium for providing services for students in schools, for example in the form of counselling services that use computers and internet networks.

In addition to opportunities those can be utilized, the development of technology also gives some challenges for school counsellors. One of the challenges, for example, is to overcome the negative impact of massive technological development on students. It is known that technological development brings two sides, namely positive and negative impacts. Hence, school counsellors specifically have additional duties so that the negative impacts can be handled properly. The negative impacts are currently found among students who use social media. The examples of negative impacts are the poor manners in communication among fellow students on social media those damage a person's psychological condition, the decrease of friendship in the real world because of using excessive communication devices, and the decline of student care for each other because cyberspace is more attractive to some students [3]. A further impact of these phenomena is the emergence of antisocial behavior among students as one of the negative impacts of technological development.

Antisocial behavior is one of the obstacles in the development of students. Antisocial behavior can cause poor interpersonal communication. Moreover, the further impact is the quality deterioration of human social interaction pattern in the future because of the weakness of caring among fellow humans [4], [5]. If this happens, humans will become less caring for others and affect the bad impacts on many aspects of life [6]. Accordingly, school counsellors must be able to take a role in handling these cases so that students in the school are able to develop optimally and have good quality of social relationship with their environment. To be succeed to combat antisocial behavior, school counsellor should develop prosocial behavior of students using counselling services. In connection with this mission, this study aims at examining the role of school counsellor in developing students' prosocial behavior.

In education, technology can make students feel more comfortable and learning materials become more interesting. 
Technology make learning fun [7]. Technology provides opportunities for students to overcome social changes, gives benefits and convenience in learning, and minimizes various limitations in learning [8]. In this regard, teachers must consider students' needs and how to prepare them. In this century, teachers are considered to be more difficult in providing subject matter. Then, teachers must incorporate technological integration in learning [2].

Furthermore, regarding prosocial behavior, these behavioral characteristics are possessing various actions those are intended to benefit others [9]. Prosocial behavior can be interpreted as a social glue that allows people of all ages to live together peacefully and productively [10]. Prosocial behavior can be measured using personal judgment peer assessment, parent or teacher assessment, and instruments [11]. Developing social behavior is one of the ways to improve the meaningfulness of life. For example, students give assistance to whom in need [12]. Thus, of course the students' prosocial behavior is influenced by many factors.

Factors influencing prosocial behavior include the influence of people around, motives for gaining cognition, and social contact [13]. This implies that socialization and social support for prosocial norms and behavior can have a strong influence on the behavior of young people [14]. Genetic and environmental influences should not to be seen as mutually contradictory explanations. Genetic elements influence prosocial behavior and individual differences in prosocial behavior [15]. A brief formulation of prosocial behavior is helping friends in their activities, sharing things with friends, helping others, and volunteering for whom in need [16].

\section{METHOD}

The research used qualitative method with ethnographic study design. It explains the ways to increase the students' prosocial behavior from the point of view of school counsellors in Indonesia. The conclusion was drawn inductively which is based on a theoretical foundation and an in-depth study carried out in the field.

\section{A. Sample and Population}

The research population were 30 school counsellors from various regions in Indonesia. The sample was drawn randomly. They are counsellors at the junior schools and senior high schools.

\section{B. Technique and Instrument}

In this research, data collection was conducted through an in-depth interview. To support the interviewers in getting answers from the interviewees, some basic questions were developed based on the theory of prosocial behavior initially developed by Eisenberg in 1982 [17]. For the purpose of analyzing content validity, few experts were asked to judge the instrument. And finally, the data obtained from the respondents were analyzed qualitatively and then concluded after being discussed before.

\section{RESUlTS AND DISCUSSION}

Based on the research, there were some descriptive data revealed. First, the thirty school counsellors as respondents here served about 7.052 students at schools in several provinces in Indonesia. Second, according to school counsellors the average of the students' prosocial ability in schools was about $60 \%$ (from ideal $100 \%$ ) that was classified as middle to low and needed to be improved in order to achieve the optimal development of students. Moreover, some of the students were having very low prosocial behavior as the counsellors stated in the interview. These students acted maladaptive in their school environment such as not showing care to others and hurting their friends physically and emotionally.

The discussion on how to improve the students' prosocial behavior in the era of technology is presented as follows.

\section{A. Urgency of Prosocial Behavior Improvement}

The data indicated that students in schools had characteristics of social behavior that were not good enough. The average of the students' prosocial ability was just $60 \%$, and of course some of them had lower percentage in their prosocial ability. It means that students' prosocial behaviors were still inadequate and the symptoms of antisocial behavior were still found. As mentioned before, antisocial behavior is an attitude of lack of care for other people who have difficulty. This condition required counsellors to help students in increasing their prosocial behavior

Antisocial behavior must be addressed by school counsellors so that it turns into prosocial behavior [18]. Some of the reasons underlying the culture of help and mutual cooperation are the characteristics of Indonesian that generally interested in social activities and respect to others. Besides that, human beings are social beings who in their life definitely need interaction and assistance from others in overcoming problems and in fulfilling their needs. Therefore, prosocial behavior should be developed so that students are able to interact and adapt better to their environment. The students' prosocial behavior is very important to be developed since prosocial attitudes and behaviors have positive impacts on various developments, including in social, affective, moral, and cognitive domains [19]. This is one of the students' developmental tasks in preparing social skills for their future life that is more complex.

\section{B. Impact of Technology Development on Students' Prosocial Behavior}

Regarding the use of technological devices by students, respondents stated that technology has a positive and negative impacts on students' prosocial behavior. The data acquired from respondents show that the use of technology affects about $75 \%$ students' prosocial behavior development. This data indicated that the effect could be positive or negative on students. Nonetheless, most of school counsellors stated that the development of technology had more negative influences that trigger the emergence of antisocial behavior in students [20]. Based on what the teachers conveyed, the negative influence is revealed to have a greater effect. Consequently, it is predicted that it tended to 
have an impact on the declining of prosocial behavior of students and conversely encourages the emergence of antisocial behavior in students.

According to the phenomenon found in the field lately, there are many parents who are complaining on their children's use of technology devices over the time. The young generation were assumed unable to use the technology devices wisely, in consequence some complaints arise. The complaints were including health problems in children, reduced social interaction between children or between children and parents, and even worse conflicts in virtual media that lead to hostility and fighting. There is a similar phenomenon that occurs in the school environment. For example, some students actually played mobile phones when the teacher was in the class delivering subject materials. If these negative things were ignored, they will remain the bad culture among the students in the future. Thus, they need to be overcome.

\section{Understand and Manage the Influencing Factors}

With regard to the phenomenon occurred, there are several factors that influence prosocial behavior of students. Based on the data obtained, these factors are categorized into two, namely internal and external factors. Internally, social behavior is influenced by genetic factors, characteristics from birth, ways of thinking, how to feel, and daily habits. There are several types of human traits that are high, medium, and low social spirits. In addition, the individual awareness and willingness to change social attitudes are also very influential because person's social attitude will not change as long as the person does not want to change. Accordingly, school counsellor must be able to improve the internal aspects of students first before giving the other strategies in increasing students' prosocial behavior.

Besides internal factors, there are factors outside the student known as external factors. These external factors also influence the development of social attitudes so that they probably tend to be prosocial or antisocial. Generally, external factors include family conditions, school conditions, and environmental conditions of the students' community. Family conditions are parenting, habituation of technology use at home, and examples or models of social attitudes in the family. The conditions in the school include the applicable rules and policies relating to the use of technology, friendship conditions, teacher education patterns, and the role of school counsellors. The conditions of the community environment are the condition of the development of technology, the culture of the community in using technology, and peers of students both in the real world and cyberspace. A research result suggested that efforts to increase prosocial behavior in students are given intensively by the family and the teacher at school.

All of these external factors can influence individual internal factors so that the students' social behavior can change. Therefore, a comprehensive understanding is needed both internally and externally as an effort to develop social behavior. The developed social behavior constitutes the positive development in students. School counsellors must look at these factors as a whole and seek cooperation with teachers, student friends, family, and society. School counsellors consider many things that are influential so that the goal of developing students' prosocial behavior can be realized.

\section{Guidance and Counselling Services to Improve the Students' Prosocial Behavior}

School counsellors interviewed stated that there were several steps that had been completed or were being carried out in an effort to develop students' prosocial behavior. They accommodated the use of technology so that the services provided are modern and in accordance with the latest conditions of students. Counselling and guidance services are divided into individual, group, and classical services. These three kinds of services engaged with materials such as caring for others, courage to apologize and forgive, friendship relations, mutual cooperation in groups, affection with others and family, good communication skills, respect for others, positive and wise use of technology, and trust in friends.

The service material is delivered to students using several types of guidance and counselling techniques. The service techniques used were role playing techniques or sociodramas, games that contained prosocial attitudes values, directing students to attend school extracurricular activities according to their talents and interests, modeling techniques either symbolically or directly, group work, and socializing attitudes which supports prosocial behavior. The use of these techniques was flexible because it adjusted the conditions of students. These techniques are supported by sophisticated technological devices that serves as the main or supporting means.

The use of technology in the services provided by school counsellors varies [21]. For example, the use of video as a medium to improve students' prosocial behavior, using films that contain values of positive social attitudes, music that supports students' improvement, making animation or short videos containing prosocial content, using social media such as Facebook and WhatsApp for counselling services, implementing e-counselling by using email or video messages, and so on. In addition, the school counsellors will use a designed website and use an android to create a program related to the increasing of prosocial behavior. Then it can be inferred that the school counsellors still continue to improve the services by constantly adjusting to technological developments.

All respondents agreed that technological developments must be used as a tool to provide the best service to students and parents. They realized that these developments will continue to occur so that it required efforts to continue learning. They also understood that technological advances have become the consequence of the emergence of science. In addition, they have a task to help students to develop, one of which is to develop of social skills. The effort can be done by accepting and adapting the technological development by the school counsellor. Then, they need to utilize these developments to achieve the goals of guidance and counselling in the school, in order to make the students are able to develop optimally and independently. This study was intended to give an overview of efforts by school counsellor 
in providing social services aimed at fostering the development of students' prosocial behavior using technological advancements.

\section{CONCLUSION}

Human needs are increasing over the years. Progress of technology also has positive and negative effects. Therefore, a strategy is needed to minimize the negative impacts and optimize the positive impacts that arise. One of the negative impacts is he low social skills of students. In the school environment there are school counsellors who can provide services to improve prosocial behavior. However, it is not only limited to school counsellors. The other teachers and parents should take part also. In summary, there are four main points to improve the students' prosocial behavior; namely the urgency of prosocial behavior, the impact of technology development on it, understanding and managing the influenced factors, and particularly school counsellors having techniques that could adapt to the enhancement of technology.

The school counsellors are suggested to apply and improve the ways of increasing the students' prosocial behavior. Other teachers and parents are also suggested to assist and support the development of students especially in their social aspects. Other researchers with similar study are suggested to assess the effectivity of the ways to increase prosocial behavior. Furthermore, every school counsellor is advised to discover new techniques of service which is related to technology utilization.

\section{CONFLICT OF INTEREST}

The authors declare no conflict of interest.

\section{AUTHOR CONTRIBUTIONS}

Abdul Kholiq prepared the research proposal, conducted the data collection, and wrote the article under the supervision of M. Solehuddin. Thus, M. Solehuddin was involved in this study since early work by reviewing and providing direct feedbacks during preparing proposal, collecting data, analyzing data, and writing the research report and article. All authors had approved the final version of this article.

\section{ACKNOWLEDGMENT}

The authors express gratitude to Lembaga Pengelola Dana Pendidikan (LPDP) (the Foundation of Education Fund Management) under the auspices of the Ministry of Finance of the Republic of Indonesia for providing research and publication fund.

\section{REFERENCES}

[1] P. Hanafizadeh, S. Ghandchi, and M. Asgarimehr, "Impact of information technology on lifestyle," International Journal of Virtual Communities and Social Networking, vol. 9, no. 2, pp. 1-23, 2017.

[2] H. Jan, "Teacher of 21st century: Characteristics and development," Research on Humanities and Social Sciences, vol. 7, no. 9, pp. 50-54, 2017.

[3] A. Strickland, "Exploring the effects of social media use on the mental health of young adults," Thesis, Major Program in Advertising and
Public Relations in the College of Sciences and in the Burnett Honors College, University of Central Florida, Orlando, Florida, 2014.

[4] C. L. Gibson and M. D. Krohn, Handbook of Life-Course Criminology: Emerging Trends and Directions for Future Research, Springer Science+Business Media New York, 2013, pp. 93-109.

[5] K. S. Sakyi, P. J. Surkan, E. Fombonne, A. Chollet, and M. Melchior, "Childhood friendships and psychological difficulties in young adulthood: an 18-year follow-up study," Eur Child Adolesc Psychiatry, 2014.

[6] H. Khalid, "The effects of social networks on pakistani students," Journal of Information Technology \& Software Engineering, vol. 7, no. 3, pp. 1-6, 2017.

[7] B. Sutton, "The effects of technology in society and education," Education and Human Development Master's Theses, Education and Human Development, The College at Brockport: State University of New York, Brockpot, New York, 2013.

[8] K. W. M. Siu, "Impact of new technology on teaching and learning in technology education: Opportunity or threat?" in Proc. Design \& Technology Association International Research Conference, 2002, pp. 29-37.

[9] Z. Manesi, N. J. Doesum, and P. A. M. VanLange, "Prosocial behavior," Encyclopedia of Personality and Individual Differences, New York: Springer, 2017, pp. 1-9.

[10] J. Lay and C. A. Hoppmann, "Altruism and prosocial," Encyclopedia of Geropsychology, Springer Science+Business Media Singapore, 2015, pp. 1-9.

[11] M. Martí-vilar, L. Corell-garcía, and C. Merino-soto, "Systematic review of prosocial behavior measures," Revista de Psicología. vol. 37, no. 1, pp. 349-377, 2019.

[12] N. Klein, "Prosocial behavior increases perceptions of meaning in life," The Journal of Positive Psychology. vol. 12, pp. 354-361, 2016.

[13] R. Baer, M. Goldman, and R. Juhnke, "Factors affecting prosocial behavior," The Journal of Social Psychology. vol. 103, no. 2, pp. 209-216, 1977.

[14] F. H. Y. Lai, A. M. H. Siu, and D. T. L. Shek, "Individual and social predictors of prosocial behavior among chinese adolescents in Hong Kong," Frontiers in Pediatrics. vol. 3, no. 39, pp. 1-8, 2015.

[15] A. Knafo and S. Israel, "Genetic and environmental contributions to children's prosocial behavior: brief review and new evidence from a reanalysis of experimental twin data," Current Opinion in Psychology. vol. 20, pp. 60-65, 2018.

[16] G. V. Caprara, P. Steca, A. Zelli, and C. Capanna, "A new scale for measuring adults' prosocialness," European Journal of Psychological Assessment. vol. 21, no. 2, pp. 77-89, 2005.

[17] N. Eisenberg, The Development of Prosocial Behavior, New York: Academic Press, 1982, pp. 77-101.

[18] G. V. Caprara et al., "Positive effects of promoting prosocial behavior in early adolescence: Evidence from a school-based intervention," International Journal of Behavioral Development. vol. 38, no. 4, pp. 386-396, 2014.

[19] G. V. Caprara, C. Barbaranelli, C. Pastorelli, A. Bandura, and P. G. Zimbardo, "Prosocial foundations of children's academic achievement," Psychological Science. vol. 11, no. 4, pp. 302-306, 2000.

[20] S. Panahi, "Impact of modernization on development of adolescents the media, culture, technology," Unique Journal of Pharmaceutical and Biological Sciences, vol. 03, no. 02, pp. 15-22, 2015.

[21] L. Hayden, T. A. Pynton, and R. A. Sabellla, "School counselors' use of technology within the ASCA national model's delivery system," Massachusetts: Somerville High School, 2007.

Copyright (C) 2020 by the authors. This is an open access article distributed under the Creative Commons Attribution License which permits unrestricted use, distribution, and reproduction in any medium, provided the original work is properly cited (CC BY 4.0).

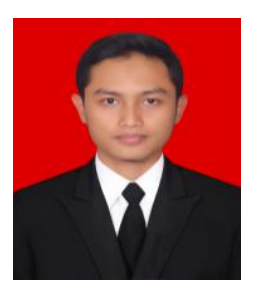

Abdul Kholiq was born in Temanggung, Indonesia. $\mathrm{He}$ graduated from undergraduate program in guidance and counseling, Semarang State University, Indonesia. Now he is a student of master degree in guidance and counselling in Indonesia University of Education.

He was a school counsellor in junior and senior high school in 2016 and 2018. He published articles entitled "The influence of students' perception on social information services and independence to self adjustment"; "The Development of Evaluation Instrument of Process Based Guidance and Counselling Program in The 
Secondary School"; and "The Program Development of Guidance and Counselling Based on Community at Semarang-Indonesia".

Mr. Kholiq was a member of Indonesia guidance and counselling student association. He granted the award of the most outstanding student and the best graduate at his faculty and campus while he was pursuing his bachelor degree. He joined several national, regional, and international conferences and won some national competition since 2014 .

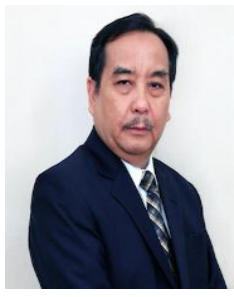

M. Solehuddin was born in Majalengka West Java Indonesia. He now is an associate professor in Guidance and Counseling Department, Faculty of Education, Indonesia University of Education. He graduated his undergraduate and graduate education in guidance and counseling in Indonesia University of Education. However, he also had ever studied in Master Degree in Early Childhood Education In Ohio State University.
In line with his educational background, his research and teaching are focusing on guidance and counseling for children. Among his curren research works are Kindergarten teachers' understanding on social justice: Stories from Indonesia, Kindergarteners' morphological awareness: Its instruction and guidance, and Post trauma counseling for early childhood teachers and tutors. 